\title{
CORRIGENDUM
}

\section{Shoulder pain following tetraplegia: a follow-up study 2-4 years after injury}

SK Salisbury, J Nitz and T Souvlis

Spinal Cord (2009) 47, 350; doi:10.1038/sc.2009.5

Correction to: Spinal Cord (2006) 44, 723-728;

doi:10.1038/sj.sc.3101908

Since the publication of the above article, the authors have noticed some errors in Table 1 . The correct table is given below:

The authors would like to apologize for this error.

Table 1 Mean pain intensity and MPQ scores

\begin{tabular}{lrr}
\hline & Mean & s.d. \\
\hline Pain intensity & 50 & 22 \\
PRIS & 13 & 8 \\
PRIA & 3 & 3 \\
PRIE & 1 & 1 \\
PRIM & 4 & 3 \\
PRIT & 21 & 14 \\
\hline
\end{tabular}

